\title{
Social cognitive deficits in male children with attention deficit hyperactivity disorder in relation to salivary oxytocin level
}

\author{
Hani H. Dessoki ${ }^{1}$, Omnia R. Amin², Mohamed R. Soltan ${ }^{3}$, Mohammed M. Abbas ${ }^{4}$ and Mariam E. Dawoud ${ }^{3 *}$ (D)
}

\begin{abstract}
Background: There is evidence supporting a pathophysiological role of oxytocin in attention deficit hyperactive disorder (ADHD) especially hyperactive and combined subtypes. It is known that children with ADHD show a high rate of social cognitive problems regarding emotion recognition. Oxytocin was assumed to play a role in the emergence of social cognition deficits in ADHD. Aim of this study is to assess social cognition (emotion recognition) deficits in relation to oxytocin level in different subtypes of ADHD among the study group. Forty male patients with ADHD were recruited from psychiatric outpatient clinic of Fayoum University Hospital, were diagnosed according to DSM-5, and were assessed using Conner's parent rating scale-revised (L). Social cognition measured by CANTAB emotion recognition task (ERT) and the level of salivary oxytocin was measured by ELISA technique.

Results: Combined subtype had been lower in correctly detecting the emotions of fear and anger. Predominately, hyperactive impulsive ADHD subtype was more rapid while detecting the emotions of surprise and disgust. There was significant negative correlation between age of onset of ADHD and errors in detecting the emotion of anger and positive correlation between age of onset of ADHD and errors in detecting the emotion of surprise. Correct detection of the emotion of happiness was associated with increased oxytocin level but the correct detection of the emotion of fear was inversely related to oxytocin level. No statistically significant difference between different subtypes of ADHD regarding salivary oxytocin level.

Conclusion: Oxytocin may play a role in social cognitive deficits in ADHD. The presence of social cognitive deficits in ADHD prompts further investigations to focus on the specificity of these deficits and in turn identify ways of managing them. Studying oxytocin in this population and its relation to social cognitive deficits can support the notion that oxytocin is a biological marker for ADHD.
\end{abstract}

Keywords: ADHD, Oxytocin, Social cognition, Emotion recognition

\section{Background}

Attention deficit/hyperactivity disorder (ADHD) is a common chronic psychiatric disorder, characterized by a pattern of developmentally inappropriate inattention, hyperactivity, and impulsivity, which affects between $5 \%$ of children and $2.5 \%$ of adults according to DSM-5 criteria [1]. ADHD can result in inappropriate social behavior, which may arise from a poorer social repertoire and

\footnotetext{
* Correspondence: med11@fayoum.edu.eg

${ }^{3}$ Psychiatry Department, Faculty of Medicine, Fayoum University, PO Box 63514, Fayoum, Egypt

Full list of author information is available at the end of the article
}

deficits in social cognitive abilities at different stages in social information processing $[2,3]$.

It is thought that deficits in face recognition, which may be due to structural abnormalities and delayed brain maturation, seen in ADHD could be one of the possible mechanisms underlying specific alterations in emotion recognition and social cognition abilities in individuals with ADHD $[4,5]$.

Oxytocin has been involved in the pathophysiology of different psychiatric disorder; one of them is ADHD $[6,7]$. Impairment in OT level in ADHD shown to be related to DA receptor derangements [8]. Plasma OT levels were reported to be lower in boys with ADHD compared with 
healthy controls, and it was suggested that the decreased levels could result in difficulties in emotion regulation and recognition of emotion observed in ADHD [9].

The aim of this study was to assess social cognition (emotion recognition) deficits in relation to oxytocin level in different subtypes of ADHD among the study group.

\section{Methods}

This was a cross-sectional study through the period from May 2017 till December 2017. Participants included in this study were 40 male patients, aged between $6-12$ years old, were diagnosed with ADHD according to the DSM-5 [1] criteria, and were recruited from psychiatric outpatient clinic, Fayoum University Hospitals. This sample size was selected to give the study a statistical power of $95 \%$ and was calculated using Epi info 7(Epi Info ${ }^{\text {tw }}$ website (http:// wwwn.cdc.gov/epiinfo/)) based on expected prevalence of ADHD and its subtypes and mean of oxytocin (OT) level among patients with ADHD obtained from previous studies, (with $95 \%$ confidence interval and precision of $5 \%$ ) in order to get maximum sample size. Patients were selected on the basis of consecutive sampling, according to their complaints, age, and being clinically average as regard IQ; then patients were diagnosed for having ADHD according to DSM-5 after completing the clinical protocol to exclude main comorbidities, endocrinal illnesses, and hormonal replacement therapy. Excluding comorbidity was important because it is known that disorders such as autism and mood or anxiety disorder could affect OT levels independent from ADHD [10].

Also, Cotter et al., [11] suggested that social cognition is impaired among large scale of neuropsychiatric disorder, and it may serve as a general biomarker indicative of neurological abnormality across a range of clinical conditions.

The patients group was designed on the basis of the information that ADHD is more prevalent in males compared with females [1]. Furthermore, it was also aimed to eliminate the intersex differences in the effect of estrogen on OT levels $[8,12]$. All patients were drug naive to avoid effect of medications on OT level [13] and also to avoid its effect on improving social cognition $[14,15]$.

First, semi-structured interview was administrated to all cases. Then, Conner's parent rating scale-revised long version CPRS-R-L [16] (Arabic version [17]) was administrated to be completed by parents to assist in determining whether children between the ages of 3 and 17 years might suffer from ADHD.

All cases were subjected to Stanford-Binet Intelligence Scales, 5th edition [18]: (Arabic version [19]) to detect IQ scales to limit the confounding influence of intellectual disability while detecting cognition. Cambridge cognition CANTAB $^{\circ}$ Emotion Recognition Task (ERT) http://www. cambridgecognition.com [20] in Arabic language was used to detect facial affect recognition using cloud-based test paradigm that assesses recognition of six universal facial expressions: happiness, sadness, anger, disgust, fear, and surprise; task computer morphed images derived from the facial features of real individuals each showing a specific emotion.

\section{Biochemical analysis}

Salivary oxytocin levels were measured using the double-antibody sandwich enzyme-linked immunosorbent assay ELISA (Human Oxytocin ELISA Kit, Beijing, China) (assay range $2 \mathrm{pg} / \mathrm{ml} \rightarrow 600 \mathrm{pg} / \mathrm{ml}$; sensitivity $1.06 \mathrm{pg} / \mathrm{ml}$ ). All participants were asked to produce passive drool. Saliva samples were collected in plain plastic tubes from participants before breakfast (at least $2 \mathrm{~h}$ fasting) after they washed their mouths, and were stored on ice throughout the session. Samples were frozen as quickly as possible during testing at the hospital refrigerator at $2-8^{\circ} \mathrm{C}$ for not more than few hours. Then samples were frozen at $-20^{\circ} \mathrm{C}$ to ensure that they remained stable during long-term storage at Laboratory of Clinical Pathology Department, Fayoum University, where the samples were assayed.

\section{Statistical analysis}

Data were statistically described in terms of mean \pm standard deviation $( \pm \mathrm{SD})$, median and range or frequencies (number of cases), and percentages when appropriate. Comparison of numerical variables between the study groups was done using Student's $t$ test for the independent samples in comparing two groups when normally distributed and Mann-Whitney $U$ test for the independent samples when not normally distributed. Comparison of numerical variables between more than two groups was done using Kruskal Wallis test with post hoc multiple 2group comparisons. For comparing categorical data, Chisquare $\left(x^{2}\right)$ test was performed. Exact test was used instead when the expected frequency is less than five [21]. Correlation between various variables was done using Spearman rank correlation equation. $p$ values less than 0.05 was considered statistically significant. All statistical calculations were done using computer programs SPSS (Statistical Package for the Social Science; SPSS Inc., Chicago, IL, USA) version 15 for Microsoft Windows.

\section{Results}

The demographic and clinical data in the study group are shown in Table 1.The age of the study group ranged from 6.3-12 years, and the mean was $8.560 \pm 1.487$. Regarding the school achievement, only $20 \%(N=8)$ was achievable in their schools. Among cases, $32.5 \%(N=13)$ had history of consanguinity. Only $30 \%(N=19)$ of cases had family history of ADHD. According to DSM-5's classification of ADHD, 37.5\% $(N=15)$ showed predominantly inattentive 
Table 1 Demographic data and clinical characteristics of the study participants

\begin{tabular}{|c|c|c|c|c|c|c|c|c|c|c|}
\hline \multicolumn{11}{|c|}{ Some of demographic data and clinical characteristics of the study participants } \\
\hline & & & \multicolumn{4}{|c|}{ No } & \multicolumn{4}{|l|}{$\%$} \\
\hline \multicolumn{11}{|l|}{$\begin{array}{l}\text { Subtypes of ADHD among case } \\
\text { group according to DSM-5 }\end{array}$} \\
\hline \multicolumn{3}{|l|}{ Predominantly inattentive } & \multicolumn{4}{|l|}{15} & \multicolumn{4}{|c|}{$37.5 \%$} \\
\hline \multicolumn{3}{|l|}{ Predominantly hyperactive } & \multicolumn{4}{|l|}{6} & \multicolumn{4}{|l|}{$15 \%$} \\
\hline \multicolumn{3}{|l|}{ Combined } & \multicolumn{4}{|l|}{19} & \multicolumn{4}{|c|}{$47.5 \%$} \\
\hline \multicolumn{11}{|l|}{ School achievement } \\
\hline Achievable & & & \multicolumn{4}{|l|}{8} & \multicolumn{4}{|l|}{$20 \%$} \\
\hline Non achievable & & & \multicolumn{4}{|l|}{32} & \multicolumn{4}{|l|}{$80 \%$} \\
\hline \multicolumn{11}{|l|}{ Consanguinity } \\
\hline Positive & & & \multicolumn{4}{|l|}{13} & \multicolumn{4}{|c|}{$32.5 \%$} \\
\hline Negative & & & \multicolumn{4}{|l|}{27} & \multicolumn{4}{|c|}{$67.5 \%$} \\
\hline \multicolumn{11}{|l|}{ Family history (FH) of ADHD } \\
\hline Positive FH & & & \multicolumn{4}{|l|}{12} & \multicolumn{4}{|l|}{$30 \%$} \\
\hline Negative FH & & & \multicolumn{4}{|l|}{28} & \multicolumn{4}{|l|}{$70 \%$} \\
\hline \multicolumn{11}{|l|}{$\begin{array}{l}\text { Data from Conner's parent } \\
\text { rating scale-revised }(\mathrm{L}) \text { items } \\
\text { among case group }\end{array}$} \\
\hline & । & & \multicolumn{2}{|l|}{$\|$} & III & & \multicolumn{2}{|l|}{ IV } & \multicolumn{2}{|l|}{ V } \\
\hline & No & $\%$ & 1 & $\%$ & No & $\%$ & No & $\%$ & No & $\%$ \\
\hline L (Inattentive) & 6 & $15 \%$ & 1 & $2.5 \%$ & 5 & $12.5 \%$ & 7 & $17.5 \%$ & 21 & $52.5 \%$ \\
\hline M (Hyperactive-Impulsive) & 9 & $22.5 \%$ & 4 & $10 \%$ & 0 & $0 \%$ & 3 & $7.5 \%$ & 24 & $60 \%$ \\
\hline N (Total) & 6 & $15 \%$ & 3 & $7.5 \%$ & 4 & $10 \%$ & 5 & $12.5 \%$ & 22 & $55 \%$ \\
\hline
\end{tabular}

I average should not be a concern, I/ slightly atypical indicates significant problem, III mildly atypical indicates significant problem, $I V$ moderately atypical indicates significant problem, $V$ markedly atypical indicates significant problem

presentation, $47.5 \%(N=19)$ showed combined presentation, and $15 \%(N=6)$ showed predominantly hyperactive presentation. Regarding classification of Conner's parent rating scale-revised (L) items among cases, 52.5\% ( $N=$ 21) of cases with predominantly inattentive ADHD subtype, $60 \%$ of cases with predominantly hyperactive impulsive ADHD subtype $(N=24)$, and $55 \%$ of cases with combined subtype $(N=22)$ were markedly atypical indicating a significant problem.

There was no significant difference between different subtypes of ADHD regarding salivary oxytocin level $(P=$ 0.279) (Table 2).

There were statistically significant differences between ADHD subtypes as regard their mean scores in the emotion recognition task ERT (total hits fear and total hits anger) in which cases with combined subtype had the least score in correctly detecting fear and anger. However, there was no statistically significant difference regarding their mean scores in the ERT (total hits happiness, sadness, surprise, disgust). Also, there were no statistically significant differences between different subtypes of ADHD regarding their mean scores in the ERT (false alarm of the six emotions) (Table 3).

Cases with hyperactive impulsive subtype showed a significant negative correlation with median reaction time of the emotion surprise $(P=0.026)$ (Fig. 1$)$ and the emotion disgust $(P=0.054)$ (Fig. 2$)$. This means that those with predominately hyperactive impulsive ADHD subtype were more rapid while detecting surprise and disgust emotions.

There was no significant correlation between subtypes of ADHD (according Conner's parent rating scale-revised (L)) and correct detection of different emotions (Table 4).

There was significant negative correlation between age of onset of ADHD and total false alarms (errors) of the emotion anger $(P=0.048)$ (Fig. 3$)$, there was significant

Table 2 Comparison of the mean salivary oxytocin level between subtypes of ADHD

\begin{tabular}{|c|c|c|c|c|c|c|c|}
\hline \multirow{2}{*}{$\begin{array}{l}\text { Oxytocin } \\
\text { level (pg/ } \\
\mathrm{ml})\end{array}$} & \multicolumn{2}{|c|}{ Predominantly inattentive type } & \multicolumn{2}{|c|}{ Predominantly hyperactive type } & \multicolumn{2}{|c|}{ Combined type } & \multirow{2}{*}{$\begin{array}{l}P \\
\text { value }\end{array}$} \\
\hline & Mean & SD & Mean & SD & Mean & $\mathrm{SD}$ & \\
\hline & 22.397 & 7.693 & 27.816 & 3.148 & 23.446 & 9.599 & 0.279 \\
\hline
\end{tabular}


Table 3 Comparison of the mean scores of total hits (correct response) and total false alarm (error in detection) of each emotion separately between different subtypes of ADHD

\begin{tabular}{|c|c|c|c|c|c|c|c|}
\hline \multirow{2}{*}{$\begin{array}{l}\text { Items of } \\
\text { ERT }\end{array}$} & \multicolumn{2}{|c|}{ Predominantly inattentive type } & \multicolumn{2}{|c|}{ Predominantly hyperactive type } & \multicolumn{2}{|c|}{ Combined type } & \multirow{2}{*}{$\begin{array}{l}P \\
\text { value }\end{array}$} \\
\hline & Mean & SD & Mean & SD & Mean & SD & \\
\hline ERTTH & 18.07 & 4.026 & 16.67 & 5.317 & 17.00 & 4.497 & 0.513 \\
\hline ERTTHH & 5.53 & 1.922 & 4.67 & 1.211 & 5.53 & 2.038 & 0.306 \\
\hline ERTTHS & 3.07 & 2.052 & 2.17 & 1.722 & 4.26 & 1.968 & 0.060 \\
\hline ERTTHF & 1.67 & 1.291 & 3.00 & 2.366 & 1.00 & 1.491 & 0.035 \\
\hline ERTTHA & 2.13 & 1.642 & 3.00 & 0.894 & 1.26 & 1.368 & 0.030 \\
\hline ERTTHSU & 4.20 & 2.145 & 2.33 & 2.503 & 3.68 & 2.335 & 0.224 \\
\hline ERTTHD & 1.47 & 1.642 & 1.50 & 1.517 & 1.26 & 1.727 & 0.778 \\
\hline ERTTFAH & 4.73 & 3.900 & 4.50 & 3.017 & 5.16 & 3.804 & 0.974 \\
\hline ERTTFAS & 6.40 & 4.222 & 6.83 & 3.656 & 8.58 & 4.718 & 0.340 \\
\hline ERTTFAF & 5.20 & 3.668 & 6.50 & 6.473 & 3.21 & 3.853 & 0.169 \\
\hline ERTTFAA & 3.87 & 2.615 & 5.83 & 4.021 & 3.37 & 2.813 & 0.421 \\
\hline ERTTFASU & 6.27 & 5.021 & 4.00 & 2.530 & 6.74 & 5.98 & 0.685 \\
\hline ERTTFAD & 3.47 & 2.722 & 3.67 & 3.386 & 3.47 & 4.623 & 0.784 \\
\hline
\end{tabular}

ERTTH ERT total hits, ERTTFAH ERT total false alarm happiness, ERTTHH ERT total hits happiness, ERTTFAS ERT total false alarm sadness, ERTTHS ERT total hits sadness, ERTTFAF ERT total false alarm fear, ERTTHF ERT total hits fear, ERTTFAA ERT total false alarm anger, ERTTHA ERT total hits anger, ERTTFASU ERT total false alarm surprise, ERTTHSU ERT total hits surprise, ERTTFAD ERT total false alarm disgust, ERTTHD ERT total hits disgust

positive correlation between age of onset of ADHD and total false alarms (errors) of the emotion surprise $(P=$ 0.04) (Fig. 4), but there were no significant correlations between age of onset of ADHD and total false alarm (errors) of the emotions (happiness, sadness, anger, and disgust). This means that the younger the age of onset of ADHD the more errors in anger recognition but less error in surprise recognition.
Only total hits of the emotion happiness showed significant positive correlation with salivary oxytocin level $(P=0.03)$. However, there was significant negative correlation between salivary oxytocin level and total hits of the emotions fear $(P=0.059)$. This means that the correct detection of happiness was associated with increased oxytocin level but the correct detection of fear was inversely related to oxytocin level (Table 5).

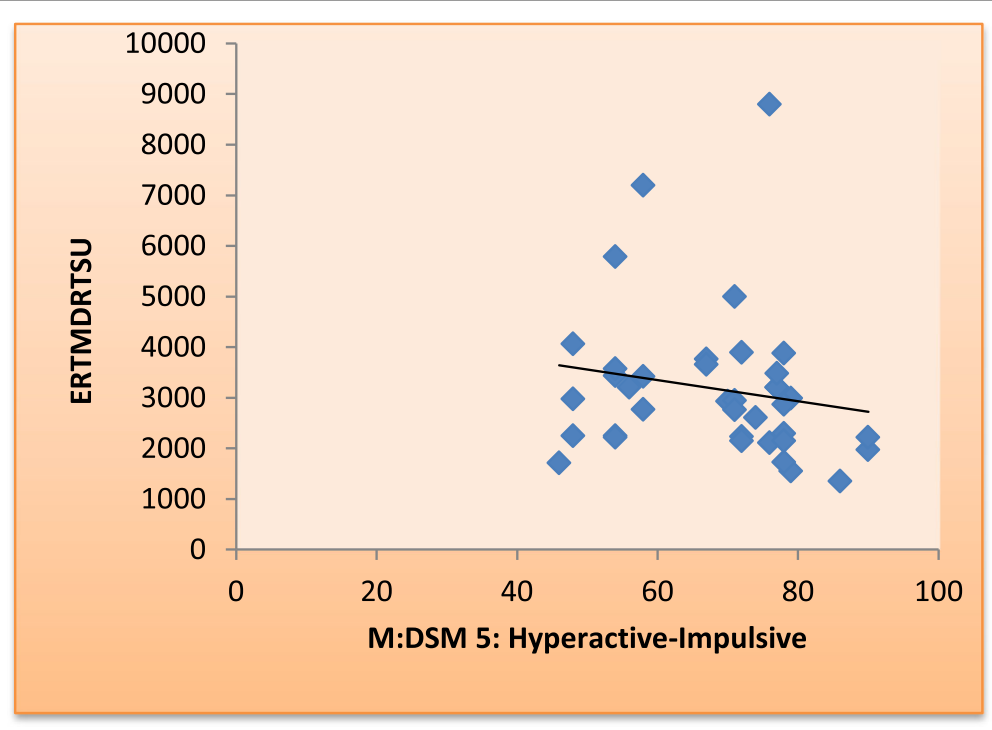

ERTMDRTSU: ERT median reaction time Surprise

Fig. 1 Scatter chart showing negative correlation between ERTMDRTSU and ADHD hyperactive impulsive subtype 


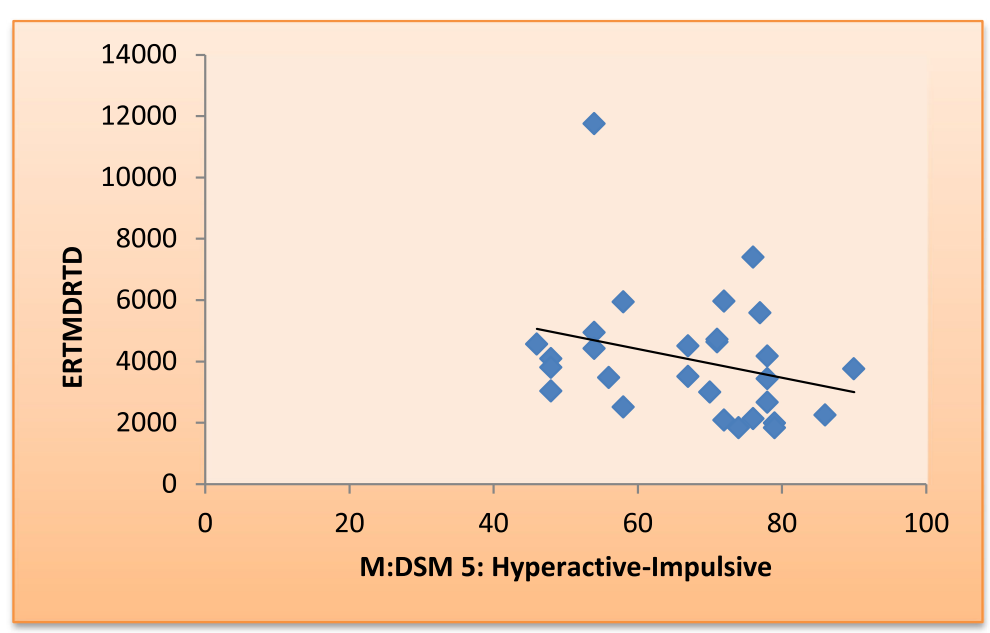

ERTMDRTD: ERT median reaction time Disgust

Fig. 2 Scatter chart showing negative correlation between ERTMDRTD and ADHD hyperactive impulsive subtype

However, there was no significant correlation between salivary oxytocin level and total hits (correct responses of the emotions (sadness, anger, surprise, disgust) or with false alarms (errors) of the six emotions) (Table 5).

\section{Discussion}

In this study, the age of the study group was selected from 6 to 12 years old. This was guided by studies in literature which studied behavioral problems and cognition in ADHD [22, 23].

This study showed that only $30 \%$ of cases had family history of ADHD. This is inconsistent with studies in many different countries, in which high heritability rates for ADHD was shown to be around 71-90\% [24-26]. This can be explained by small sample size. Also, it is not an epidemiological study. It is worth noting that not all of the risk for ADHD is genetic, and estimates of heritability also include an element of gene environment

Table 4 Correlation between subtypes of ADHD according Conner's parent rating scale- revised $(\mathrm{L})$ and items of ERT (total hits and total hits of each emotion separately)

\begin{tabular}{|c|c|c|c|c|c|c|}
\hline \multirow[t]{2}{*}{ ERT } & \multicolumn{2}{|l|}{$\mathrm{L}$} & \multicolumn{2}{|l|}{ M } & \multicolumn{2}{|l|}{$\mathrm{N}$} \\
\hline & $\bar{R}$ & $P$ value & $\bar{R}$ & $P$ value & $\bar{R}$ & $P$ value \\
\hline$\overline{\text { ERTTH }}$ & 0.095 & 0.561 & -0.007 & 0.966 & 0.044 & 0.785 \\
\hline ERTTHH & 0.165 & 0.309 & 0.228 & 0.156 & 0.258 & 0.108 \\
\hline ERTTHS & 0.123 & 0.450 & -0.043 & 0.792 & 0.121 & 0.458 \\
\hline ERTTHF & -0.193 & 0.234 & -0.094 & 0.565 & -0.224 & 0.164 \\
\hline ERTTHA & -0.239 & 0.138 & -0.184 & 0.255 & -0.288 & 0.072 \\
\hline ERTTHSU & 0.202 & 0.212 & 0.087 & 0.594 & 0.139 & 0.391 \\
\hline ERTTHD & -0.078 & 0.634 & -0.036 & 0.824 & -0.090 & 0.580 \\
\hline
\end{tabular}

ERTTH ERT total hits, ERTTHH ERT total hits happiness, ERTTHS ERT total hits sadness, ERTTHF ERT total hits fear, ERTTHA ERT total hits anger, ERTTHSU ERT total hits surprise, ERTTHD ERT total hits disgust, $L$ DSM-IV: inattentive, $M$ DSMIV: hyperactive-impulsive, N DSM-IV: total interaction. It is estimated that between 10 to $40 \%$ of the variance associated with ADHD is accounted for environmental factors [27]

This study showed that $37.5 \%(N=15)$ showed predominantly inattentive presentation (ADHD-PI) and $47.5 \%(N=19)$ showed combined presentation (ADHD$\mathrm{CT})$. This is in line with clinic samples prevalence but not with results in community prevalence. In clinic samples, ADHD-CT is approximately one and one half times more prevalent than ADHD-PI. Although predominantly inattentive type (ADHD-PI) appears to be more prevalent in the general population, children diagnosed with ADHD-CT are more likely to be referred for treatment probably reflecting the greater amount of disruptive behavior associated with the ADHD-CT symptoms [28].

This study showed that there was no significant difference between oxytocin levels in different ADHD subtypes (Table 2). This is inconsistent with Insel, [29] who found that among the ADHD subtypes, the ADHD-PI subtype had a significantly higher serum OT level than the ADHD-HI subtype. Demirci et al., [22] also supported this and explained that reduced OT levels in the ADHD-HI subtype may cause high aggression and lower empathy in boys. This inconsistence may be explained by using salivary samples which may not reflect CNS OT levels and also, could be explained by small sample size.

There was significant difference between ADHD subtypes as regard the total number of correct responses (times the subject correctly selected the emotion anger and fear), where subjects with predominately hyperactive impulsive ADHD subtype (ADHD-HI) were the better performers, and subjects with combined presentation (ADHD-CT) were the worst (Table 3). This is in line with a study conducted by Kemp and Korkman, [30] who assessed emotion recognition using NEPSY-II and 


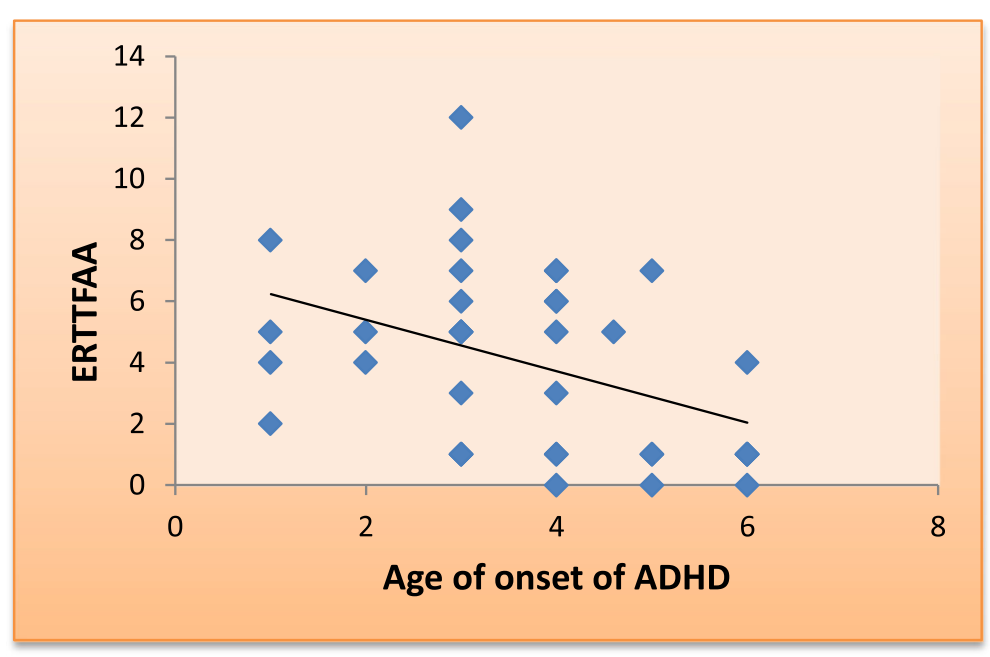

ERTTFAA: ERT total false alarm Anger

Fig. 3 Scatter chart showing negative correlation between age of onset of ADHD and ERTTFAA

found that ADHD-CT performed significantly lower in affect recognition subtest. Also, consistent with metaanalysis study conducted by Bora and Pantelis, [31] who concluded that the most robust facial emotion recognition deficits were evident in anger and fear, yet they did not study them among different ADHD subtypes.

However, this is inconsistent with Yuill and Lyon, [32] who showed that impaired emotional processing in children with ADHD is unrelated to general cognitive limitations, such as impulsivity and inattentiveness, which affect the subtypes of ADHD [33]. Also, this is inconsistent with the findings of Pelc et al., [34] who found that children with the ADHD-HI subtype, in particular, make more mistakes in recognition of emotional facial expression; they particularly experience problems in recognizing facial expressions representing anger and sadness. Also, inconsistent with reports of Schwenck et al., [35] who concluded that there was no difference among the ADHD subtypes with respect to recognition of emotions. This inconsistence may be explained by different methodologies in studies which were used to detect social cognitive domains. Tasks for the assessment of social cognition varied and included affective adult and child faces, timed or nontimed presentations, cross-matching tasks, matching faces to emotional stories and matching emotions to eyes, different social backgrounds, and socioeconomic status. Also, different age group among researches may be operative.

Hyperactive impulsive ADHD subtype was associated with rapid speed in detection of the emotions (surprise, disgust) (Figs. 1, 2 respectively). This finding is closely

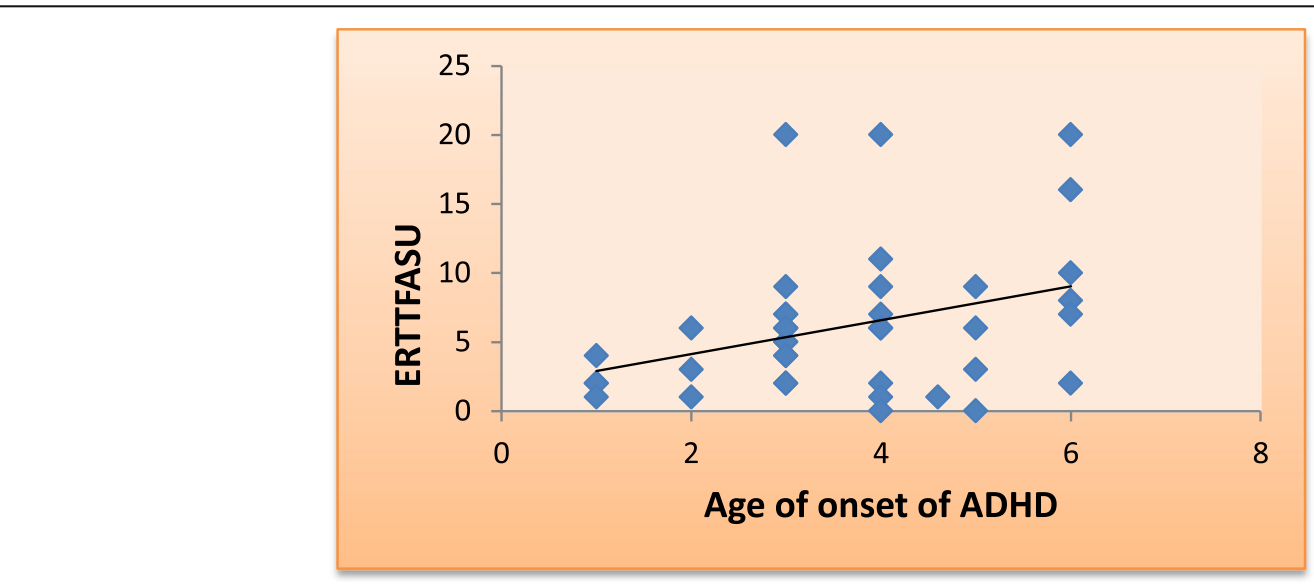

ERTTFASU: ERT total false alarm Surprise

Fig. 4 Scatter chart showing positive correlation between age of onset of ADHD and ERTTFASU 
Table 5 Correlation between salivary oxytocin level and items of ERT (total hits, total hits and false alarm for each emotion separately)

\begin{tabular}{lll}
\hline ERT & Oxytocin level & \\
\cline { 2 - 3 } & $R$ & $P$ value \\
\hline ERTTH & -0.153 & 0.176 \\
ERTTHH & 0.232 & 0.038 \\
ERTTHS & -0.144 & 0.201 \\
ERTTHF & -0.188 & 0.059 \\
ERTTHA & 0.073 & 0.521 \\
ERTTHSU & -0.041 & 0.718 \\
ERTTHD & -0.052 & 0.649 \\
ERTTFAH & -0.073 & 0.521 \\
ERTTFAS & 0.166 & 0.141 \\
ERTTFAF & 0.055 & 0.631 \\
ERTTFAA & 0.129 & 0.255 \\
ERTTFASU & 0.104 & 0.359 \\
ERTTFAD & -0.064 & 0.574 \\
\hline
\end{tabular}

ERTTH ERT total hits, ERTTFAH ERT total false alarm happiness, ERTTHH ERT total hits happiness, ERTTFAS ERT total false alarm sadness, ERTTHS ERT total hits sadness, ERTTFAF ERT total false alarm fear, ERTTHF ERT total hits fear, ERTTFAA ERT total false alarm anger, ERTTHA ERT total hits anger, ERTTFASU ERT total false alarm surprise, ERTTHSU ERT total hits surprise, ERTTHD ERT total hits Disgust, ERTTFAD ERT total false alarm disgust

related to findings of a study that examined visual and auditory emotion recognition in a wide scale of children and adolescents with ADHD which was conducted by Waddington et al., [36]. The latter study showed that speed of visual and auditory emotion recognition was positively correlated with hyperactivity and inattention on Conner's parent rating scale, and speed of auditory emotion recognition positively correlated with inattention on the Conner's teacher rating scale; however, the latter study did not specify each emotion separately. A study conducted by Tehrani-Doost et al., [37] found that the time spent in recognizing happy faces was higher in the ADHD group; however, the relation between the time needed to detect the emotion and different ADHD was not studied in this research. However, these study results are expected as patients with ADHD hyperactive impulsive subtype are characterized by being reluctant in doing effort and usually make rapid and impulsive decisions. This inconsistence may be due to the different methodologies and different assessment settings.

There was no correlation between subtypes of ADHD and the total number of correct responses of emotions (happiness, sadness, fear, anger, surprise, and disgust) (Table 4). These findings were inconsistent with that of the study conducted by Tehrani-Doost et al., [37] which showed that inattention associated with a considerable effect on detection of both angry and sad targets, also found significant negative association of hyperactivity- impulsivity with anger detection. Another study showed that hyperactivity measures were positively correlated with the recognition of disgust and inversely correlated with the recognition of fear [4]. This inconsistence may be due to small sample size and using only one task for assessment of social cognition (emotion recognition) in which only one social cognitive domain was assessed.

In this study, the earlier onset was associated with more errors in anger detection (Fig. 3) yet less errors in surprise detection (Fig. 4). A meta-analysis conducted by Bora and Pantelis, [31] showed that social cognitive deficits in emotion recognition and theory of mind (ToM) were very subtle and non-significant respectively in adults with ADHD. There is some evidence that aspects of social cognition like affect perception deficits are present in younger but not older patients with ADHD. In an early study by Shapiro et al., [38], the author concluded that this finding reflects a developmental improvement in allocation of attention resources or the implementation of compensatory strategies to cope with the emotion perception deficit; this was also supported by Guyer et al., [39] who did not yield significant affect recognition deficits in patients aged 12 or older. This is inconsistent with Waddington et al., [36] who found that older patients with ADHD unexpectedly showed poorer emotion recognition than children with ADHD.

This study showed that there was significant positive correlation between salivary OT levels and total hits (correct responses) of the emotion happiness; also, there was significant negative correlation between salivary OT levels and total hits fear (correct responses) (Table 5). In a study conducted by Feeser et al., [40], the administration of intranasal OT improved recognition of avoidance-related facial expressions of emotions (fear, sadness, and disgust) but had no effect on approach-related expressions of emotion (happy, angry, and surprise). In other studies, OT improves only specific emotions such as facial expressions of happiness [41], fear [42], or anger [43], which may conclude the possible relation between OT level and emotion recognition.

Examination of different age groups, males, females, and interventional studies in a large sample may be helpful in accurate assessment of this relation and its role in improvement of ADHD deficits.

This study was based on sample size calculation so results constitute statistical power. Including only boys to reduce the impact of estrogen on social cognition and OT level lessened confounding factors. Using a well-validated tool to measure social cognition which is used to assess multiple dimensions of affect recognition including reaction time, correct responses, incorrect responses, and assessment of secondary emotions, such as surprise, and positive emotions, such as happiness, also, it was interesting for the participants being iPad application.

The use of cross-sectional studies can prevent drawing conclusions about causal relationships. Reliance on only 
semi-structured clinical interview without using standardized structured diagnostic tool may affect diagnosis; also, comorbid conditions may be missed; this can affect our results as many other psychiatric conditions can affect social cognition and OT level. Using salivary OT rather than cerebrospinal fluid (CSF) might not have completely reflected OT action in the CNS because the relationship between peripheral and central levels of OT is unclear.

\section{Conclusion}

This study concluded that oxytocin may play a role in social cognitive deficits and also supported the possible difference between ADHD subtypes in affect recognition as those with combined subtype may affect anger and fear recognition. Further studies are needed to find the possible effect of social cognitive deficits in ADHD presentations and impairments. Investigational studies are needed to find the possible therapeutic role of oxytocin in ADHD.

\section{Abbreviations}

ADHD: Attention deficit hyperactive disorder; ADHD-CT: ADHD combined type; ADHD-HI: ADHD hyperactive type; ADHD-PI: ADHD predominantly inattentive; CANTAB: Cambridge Neuropsychological Test Automated Battery

\section{Acknowledgements}

The authors thank Cambridge Neuropsychological Test Automated Battery for the help with the emotion recognition task

\section{Authors' contributions}

MD analyzed and interpreted the patient data regarding the clinical data and psychometric tools and was a major contributor in writing the manuscript. MA performed the clinical pathology examination of the salivary samples. All authors read and approved the final manuscript.

\section{Funding}

This study did not receive any fund.

\section{Availability of data and materials}

Data sharing is not applicable to this article as no datasets were generated or analysed during the current study.

\section{Ethics approval and consent to participate}

This study was approved by the Ethics Committee of Faculty of Medicine, Fayoum University. Child assents and parents' consent were obtained from both the participants and their parents. The number of approval is not applicable.

\section{Consent for publication}

Not applicable.

\section{Competing interests}

The authors declare that they have no competing interests.

\section{Author details}

${ }^{1}$ Psychiatry Department, Faculty of Medicine, Beni Suef University, Beni Suef Egypt. ${ }^{2}$ Psychiatry Department, Faculty of Medicine, Cairo University, Cairo, Egypt. ${ }^{3}$ Psychiatry Department, Faculty of Medicine, Fayoum University, PO Box 63514, Fayoum, Egypt. ${ }^{4}$ Clinical Pathology Department, Faculty of Medicine, Fayoum University, Fayoum, Egypt.
Received: 8 January 2020 Accepted: 14 February 2020

Published online: 31 March 2020

\section{References}

1. American Psychiatric Association (2013) Diagnostic and statistical manual of mental disorders, 5th edn. American Psychiatric Association, Washington, DC

2. Nijmeijer JS, Minderaa RB, Buitelaar JK, Mulligan A, Hartman CA, Hoekstra PJ (2008) Attention-deficit/hyperactivity disorder and social dysfunctioning. Clin Psychol Rev 28(4):692-708

3. Uekermann J, Kraemer M, Abdel-Hamid M, Schimmelmann BG, Hebebrand J, Daum I et al (2010) Social cognition in attention-deficit hyperactivity disorder (ADHD). Neurosci Biobehav Rev 34(5):734-743

4. Aspan N, Bozsik C, Gadoros J, Nagy P, Inantsy-Pap J, Vida P, Halasz J (2014) Emotion recognition pattern in adolescent boys with attention-deficit/ hyperactivity disorder. BioMed Res Int

5. Demirci E, Erdogan A (2016) Is emotion recognition the only problem in ADHD? Effects of pharmacotherapy on face and emotion recognition in children with ADHD. ADHD Attention Deficit Hyperactivity Dis 8(4):197-204. https://doi.org/10.1007/s12402-016-0201-x

6. Maoz H, Tsviban L, Gvirts HZ, Shamay-Tsoory SG, Levkovitz Y, Watemberg N, Bloch $Y$ (2014) Stimulants improve theory of mind in children with attention deficit/hyperactivity disorder. J Psychopharmacol 28(3):212-219

7. Sasaki T, Hashimoto K, Oda Y, Ishima T, Kurata T, Takahashi J et al (2015) Decreased levels of serum oxytocin in pediatric patients with attention deficit/hyperactivity disorder. Psychiatry Res 228(3):746-751

8. Demirci E, Özmen S, Öztop DB (2016) Relationship between impulsivity and serum oxytocin in male children and adolescents with attention-deficit and hyperactivity disorder: a preliminary study. Nöro Psikiyatri Arşivi 53(4):291. https://doi.org/10.5152/npa.2015.10284

9. Taurines R, Schwenck C, Lyttwin B, Schecklmann M, Jans T, Reefschläger $L$ et al (2014) Oxytocin plasma concentrations in children and adolescents with autism spectrum disorder: correlation with autistic symptomatology. ADHD Atten Deficit Hyperactivity Dis 6(3):231-239

10. Turan T, Uysal C, Asdemir A, Kılıç E (2013) May oxytocin be a trait marker for bipolar disorder? Psychoneuroendocrinology 38(12):2890-2896

11. Cotter J, Granger K, Backx R, Hobbs M, Looi CY, Barnett JH (2017) Social cognitive dysfunction as a clinical marker: a systematic review of metaanalyses across 30 clinical conditions. Neurosci Biobehav Rev. https://doi. org/10.1016/j.neubiorev.2017.11.014

12. Zak PJ, Fakhar A (2006) Neuroactive hormones and interpersonal trust: international evidence. Econ Hum Biol 4(3):412-429

13. Appenrodt E, Bojanowska E, Janus J, Stempniak B, Guzek JW, Schwarzberg H (1997) Effects of methylphenidate on oxytocin and vasopressin levels in pinealectomized rats during light-dark cycle. Pharmacol Biochem Behav 58(2):415-419

14. Schmid Y, Hysek CM, Simmler LD, Crockett MJ, Quednow BB, Liechti ME (2014) Differential effects of MDMA and methylphenidate on social cognition. J Psychopharmacol 28(9):847-856 https://doi.org/10.1177/ 0269881114542454

15. Dolder PC, Strajhar P, Vizeli P, Odermatt A, Liechti ME (2018) Acute effects of lisdexamfetamine and D-amphetamine on social cognition and cognitive performance in a placebo-controlled study in healthy subjects. Psychopharmacology 235(5):1389-1402 https://doi.org/10.1007/s00213-0184849-0

16. Conners CK (1997) Conners' rating scales-revised. Multi-Health Systems, North Tonawanda, New York

17. El-Sheikh M, Sadek A, Omar A, Nahas G (2002) Psychiatric morbidity in first degree relatives of ADHD children. Unpublished MD thesis, Ain Shams University Back to cited text, vol 16

18. Bain SK, Allin JD (2005) Book review: Stanford-binet intelligence scales. J Psychoeducational Assess 23(1):87-95

19. Farag (2010) Stanford-Binet Intelligence Test: Arabic version. Anglo Press, Cairo

20. Cambridge cognition. CANTAB ${ }^{\circledR}$ Emotion Recognition Task (ERT) (2012). http://www.cambridgecognition.com

21. Chan YH (2003) Biostatistics 102: quantitative data: parametric \& nonparametric tests. Singapore Med J 44(8):391-396

22. Demirci E, Özmen S, Kilic E, Öztop DB (2015) The relationship between aggression, empathy skills and serum oxytocin levels in male children and adolescents with attention deficit and hyperactivity disorder. Behav Pharmacol 27(8):681-688. https://doi.org/10.1097/FBP.0000000000000234 
23. Tye C, Bedford R, Asherson P, Ashwood KL, Azadi B, Bolton P, McLoughlin G (2017) Callous-unemotional traits moderate executive function in children with ASD and ADHD: a pilot event-related potential study. Dev Cogn Neurosci 26:84-90

24. Faraone SV, Perlis RH, Doyle AE, Smoller JW, Goralnick JJ, Holmgren MA, Sklar P (2005) Molecular genetics of attention-deficit/hyperactivity disorder. Biol Psychiatry 57(11):1313-1323

25. Nikolas MA, Burt SA (2010) Genetic and environmental influences on ADHD symptom dimensions of inattention and hyperactivity: a meta-analysis. J Abnormal Psychol 119(1):1-17. https://doi.org/10.1037/a0018010

26. Thapar A, Cooper M, Eyre O, Langley K (2013) Practitioner review: what have we learnt about the causes of ADHD? J Child Psychol Psychiatr 54(1):3-16

27. Banerjee TD, Middleton F, Faraone SV (2007) Environmental risk factors for attention-deficit hyperactivity disorder. Acta Paediatrica 96(9):1269-1274

28. Milich R, Balentine AC, Lynam DR (2001) ADHD combined type and ADHD predominantly inattentive type are distinct and unrelated disorders. Clin Psychol 8(4):463-488

29. Insel TR (2010) The challenge of translation in social neuroscience: a review of oxytocin, vasopressin, and affiliative behavior. Neuron 65(6):768-779. https://doi.org/10.1016/j.neuron.2010.03.005

30. Kemp SL, Korkman M (2010) Essentials of NEPSY-II assessment (Vol. 69). Wiley

31. Bora E, Pantelis C (2016) Meta-analysis of social cognition in attentiondeficit/hyperactivity disorder (ADHD): comparison with healthy controls and autistic spectrum disorder. Psychol Med 46(4):699-716. https://doi.org/10. 1017/S0033291715002573

32. Yuill N, Lyon J (2007) Selective difficulty in recognising facial expressions of emotion in boys with ADHD. Eur Child Adolesc Psychiatr 16(6):398-404

33. Katz-Gold I, Besser A, Priel B (2007) The role of simple emotion recognition skills among school aged boys at risk of ADHD. J Abnormal Child Psychol 35(3):363-378

34. Pelc K, Kornreich C, Foisy ML, Dan B (2006) Recognition of emotional facial expressions in attention-deficit hyperactivity disorder. Pediatric Neurol 35(2): 93-97

35. Schwenck C, Schmitt D, Sievers S, Romanos M, Warnke A, Schneider W (2011) Cognitive and emotional empathy in children with ADHD and conduct disorder. Zeitschrift fur Kinder-und Jugend psychiatrie und Psychotherapie 39(4):265-276

36. Waddington F, Hartman C, de Bruijn Y, Lappenschaar M, Oerlemans A, Buitelaar J et al (2018) Visual and auditory emotion recognition problems as familial cross-disorder phenomenon in ASD and ADHD. Eur Neuropsychopharmacol 28(9):994-1005

37. Tehrani-Doost M, Noorazar G, Shahrivar Z, Banaraki AK, Beigi PF, Noorian N (2017) Is emotion recognition related to core symptoms of childhood ADHD? J Can Acad Child Adolescent Psychiatr 26(1):31-38

38. Shapiro EG, Hughes SJ, August GJ, Bloomquist ML (1993) Processing of emotional information in children with attention-deficit hyperactivity disorder. Dev Neuropsychol 9(3-4):207-224

39. Guyer AE, McClure EB, Adler AD, Brotman MA, Rich BA, Kimes AS et al (2007) Specificity of facial expression labeling deficits in childhood psychopathology. J Child Psychol Psychiatr 48(9):863-871

40. Feeser M, Fan Y, Weigand A, Hahn A, Gärtner M, Aust S et al (2014) The beneficial effect of oxytocin on avoidance-related facial emotion recognition depends on early life stress experience. Psychopharmacology 231(24):4735-4744. https://doi.org/10.1007/s00213-014-3631-1

41. Marsh AA, Henry HY, Pine DS, Blair RJR (2010) Oxytocin improves specific recognition of positive facial expressions. Psychopharmacology 209(3):225232

42. Fischer-Shofty M, Shamay-Tsoory SG, Harari H, Levkovitz Y (2010) The effect of intranasal administration of oxytocin on fear recognition. Neuropsychologia 48(1):179-184. https://doi.org/10.1016/j.neuropsychologia. 2009.09.003

43. Quintana DS, Westlye LT, Rustan $\varnothing \mathrm{G}$, Tesli N, Poppy CL, Smevik H et al (2015) Low-dose oxytocin delivered intranasally with Breath Powered device affects social-cognitive behavior: a randomized four-way crossover trial with nasal cavity dimension assessment. Translat Psychiatr 5(7):e602. https://doi. org/10.1038/tp.2015.93

\section{Publisher's Note}

Springer Nature remains neutral with regard to jurisdictional claims in published maps and institutional affiliations.

\section{Submit your manuscript to a SpringerOpen ${ }^{\circ}$ journal and benefit from:}

- Convenient online submission

- Rigorous peer review

- Open access: articles freely available online

- High visibility within the field

- Retaining the copyright to your article

Submit your next manuscript at $\boldsymbol{\nabla}$ springeropen.com 